\title{
Microstructural and Elastic Properties of Stable Aluminium-rich TiAl and TiAl2 Formed Phase Intermetallics
}

*Nicholas O. Ongwen ${ }^{a}$ Daoud Chanbi ${ }^{b}$ Erick Ogam ${ }^{c}$ Henry O. Otunga ${ }^{a}$ Andrew O. Oduor $^{\mathrm{a}}$ Z. E. A. Fellah

(a) Department of Physics and Materials Science, Maseno University, Kenya.

(b) Laboratoire d'Electrochimie, Corrosion, Métallurgie et Chimie Minérale, Université des Sciences et de la technologie de Houari Boumediene, Algeria.

(c) Laboratoire de Mécanique et d'Acoustique, LMA-UMR 7031 Aix-Marseille University-CNRS-Centrale Marseille, F-13453 Marseille CEDEX 13, France.

\begin{abstract}
We studied aluminium-rich $\mathrm{Ti}-\mathrm{Al}\left(\mathrm{Ti}_{32} \mathrm{Al}_{68}\right.$ and $\left.\mathrm{Ti}_{40} \mathrm{Al}_{60}\right)$ binary alloys that were composed of $\mathrm{TiAl}$ and $\mathrm{TiAl}_{2}$ lamellar microstructures. The law of mixtures was employed in calculating the theoretical Young's moduli. The lattice parameters of the alloys showed that both were tetragonal crystals. In the computational study, we made use of our modified method for the stress-strain calculation of elastic constants. The alloys at the respective chemical compositions were modelled by creating titanium (Ti) supercells, which were then doped by replacing some of the Ti atoms with aluminium atoms. The values of elastic moduli were verified by the ab initio calculation in this work, which showed a perfect agreement. The Pugh's ratio showed that both the alloys are ductile.
\end{abstract}

Keywords: Intermetallics; $\mathrm{Ti}_{32} \mathrm{Al}_{68}$ and $\mathrm{Ti}_{40} \mathrm{Al}_{60}$ Alloys; Elastic properties; $\mathrm{Ab}$-initio calculations; Aerospace materials; automotive materials. 


\subsection{Introduction}

Aluminium (Al) is a highly attractive material in the industrial world, especially where light-weight and corrosion-resistance is required. However, some of its properties which limit its applications include its poor mechanical properties such as low Young's modulus. One of the most-challenging areas in aircraft and automotive industry is to find materials with both low density as well as high stress and high melting point. Ti-Al alloys are hard to be applied directly in practice in the industry due to their brittleness and plastic deformation [1]

In our recent work [2], we did an experimental study of the Young's moduli of $\mathrm{Ti}_{32} \mathrm{Al}_{68}$ and $\mathrm{Ti}_{40} \mathrm{Al}_{60}$ binary alloys using Resonance Ultrasonic Vibration. However, the choice of the resonance family of modes of vibrations were guided by the ab initio study of the elastic moduli of Ti and Al that make up the alloys. Thus, the values of the Young's moduli obtained needed verification. Moreover, the experimental study did not explore the crystal structures and the lattice parameters of the synthesized alloy samples. In this work, our objectives were (i) to verify the experimental values of the Young's moduli, (ii) to determine the experimental values of the lattice parameters and (iii) to explore the brittle/ ductile nature of the binary alloys.

\subsection{Materials and methods}

The experimental detail for obtaining the Young's moduli of the binary alloys has already been explained in our earlier work [2], where the energy dispersive spectrometer was used to determine the chemical compositions of the prepared alloy samples, which we have used in the ab initio calculation in this work. Fig. 1 shows the 
diffractograms obtained from the experimental study, together with the indexed peaks as well as the dual-phase nature of the alloys.
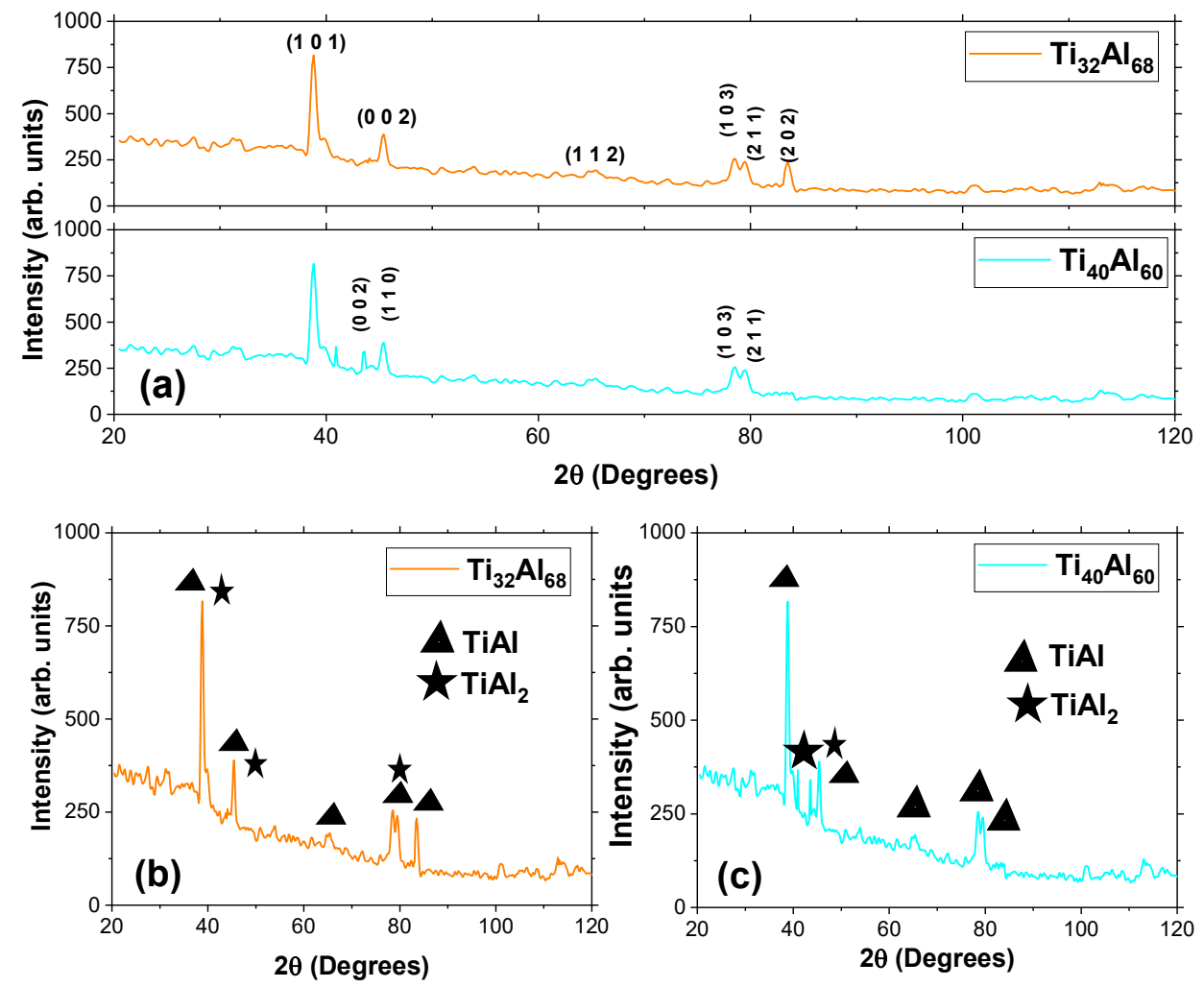

Fig. 1: (a) X-ray diffractograms for the indexed peaks for calculating the lattice parameters of the two binary alloys; and (b and c) the identified phases (TiAl and $\left.\mathrm{TiAl}_{2}\right)$.

\subsection{Structural study}

First-principles calculations were performed using Quantum Espresso code. We started the modelling of the structures with a Ti unit cell, which adopts a simple cubic structure with an Im-3m space group (number 229), consisting of 2 atoms [3]. We then created 2 x $2 \times 3$ supercells, which consisted of 24 atoms. The supercells were then doped by replacing some of the $\mathrm{Ti}$ atoms with appropriate number of atoms of $\mathrm{Al}$. The experimental Scanning Electron Microscopic (SEM) images are shown in Fig. 2, which 
also revealed the dual-phase nature of the $\mathrm{Ti}_{32} \mathrm{Al}_{68}$ and the $\mathrm{Ti}_{40} \mathrm{Al}_{60}$ binary alloys. It is clearly visible in Fig. 2 that the elongated plates of the $\mathrm{TiAl}_{2}$ phase are separated in fragments by the TiAl phase, which shows that the TiAl phase penetrates through the $\mathrm{TiAl}_{2} / \mathrm{TiAl}_{2}$ grain boundaries and separates the $\mathrm{TiAl}_{2}$ grains from each other. This behaviour of the grain boundary phases is related with the so-called complete and incomplete wetting of grain boundaries by the second solid phase [4]. Fig. 2 shows that the concentration of $\mathrm{Ti}$ for the $\mathrm{TiAl}_{2}$ phase in the two binary alloys is $56.91 \%$. Thus, we also calculated the elastic constants of the $\mathrm{TiAl}_{2}$ phase.

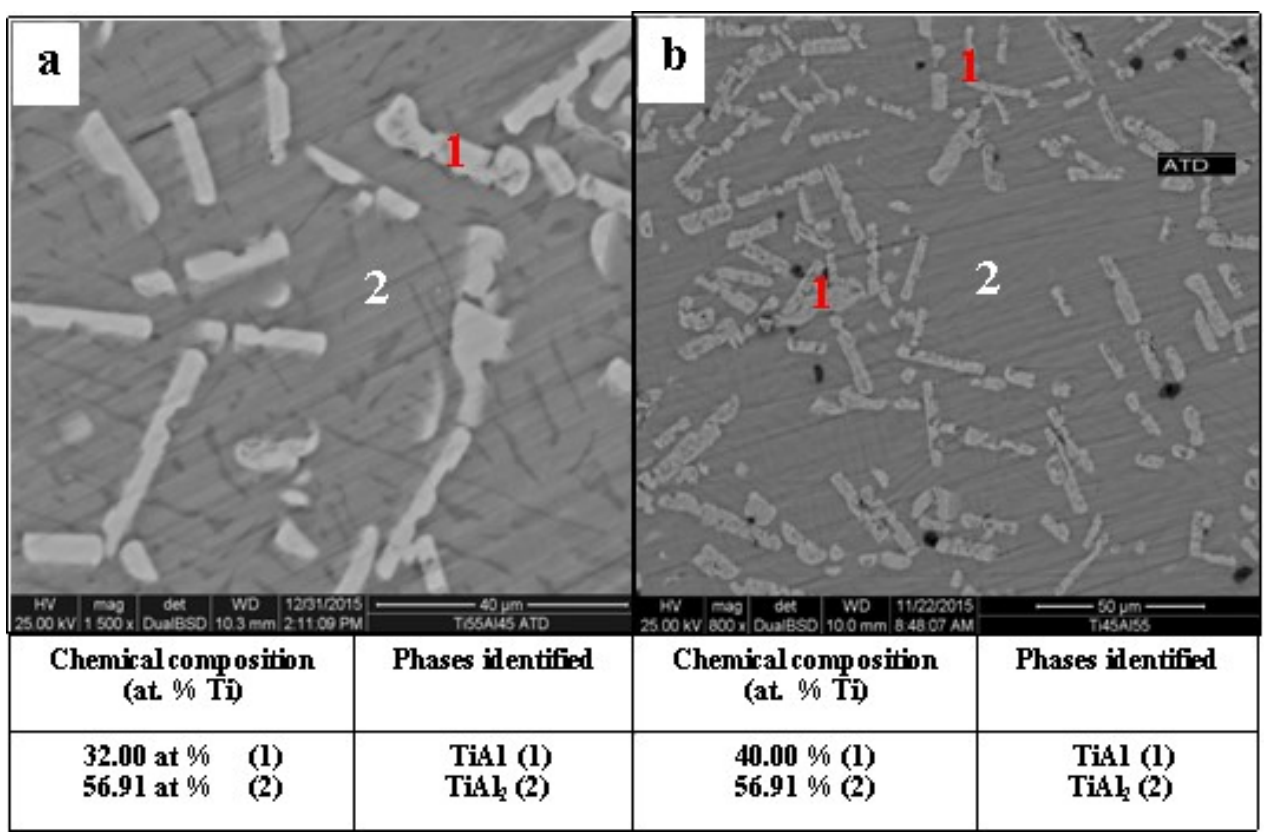

Fig. 2: SEM micrographs of binary alloy phases (a) $\mathrm{Ti}_{32} \mathrm{Al}_{68}$ and $\mathrm{TiAl}_{2}$ (b) $\mathrm{Ti}_{40} \mathrm{Al}_{60}$ and $\mathrm{TiAl}_{2}$

The electron-ion interactions were described by scalar-relativistic, norm-conserving ultrasoft pseudopotentials. The calculation employed generalized gradient approximation, with PBESOL functionals [5]. 


\subsection{Calculation of elastic constants}

Details of the calculation are found in our recent work [6]. The brittle and ductile behaviour of a material can be determined using the Poisson's ratio as well as the Pugh's ratio (Eqn. 1) [7]. If $\mathrm{n}>1.75$, the material is ductile. Otherwise, the material is brittle.

$$
\frac{\mathrm{B}}{\mathrm{G}}=\mathrm{n},
$$

where $\mathrm{n}$ is a constant called the Pugh's modulus ratio. For the Poisson's ratio, a value of 0.27 and above predicts the ductile nature of materials, while a value less than 0.27 predicts that the material is ductile [8].

\section{Results and discussion}

The XRD diffractograms for calculating the elastic constants of the formed binary alloys (Fig. 1), shows that both the alloys had growth orientation along the $\left(\begin{array}{lll}1 & 0 & 1\end{array}\right)$ direction in the tetragonal structure. From Table 1, it can be observed that the computed values are in very good agreement with the experimental values. However, the computed values of the lattice parameters as well as the unit cell volumes are generally lower than those of the experimental values. This can be attributed to the fact that DFT is a ground state theory, which means that the computed values were obtained at the ground state, while the experimental values were obtained at room temperature.

Table 1: Equilibrium lattice parameters (in $\AA$ ) and unit cell volumes (in $\AA^{3}$ ) from the XRD analysis and the computational study, as well as the computed densities (in $\mathrm{kg} / \mathrm{m}^{3}$ ). Also presented are the experimental and computational values of the elastic 
moduli (in GPa), the Poisson's ratio ( $\mu$ ) and the Pugh's ratio (n), together with some values in the literature.

\begin{tabular}{|l|l|l|l|}
\hline Alloy & Parameter & Computation & Experiment \\
\hline Ti32Al68 & $\mathrm{a}(\AA)$ & 2.831 & 2.822 \\
\cline { 2 - 4 } & $\mathrm{c}(\AA)$ & 3.979 & 4.056 \\
\cline { 2 - 4 } & $\mathrm{V}\left(\AA^{3}\right)$ & 318.9 & 323.0 \\
\cline { 2 - 4 } & $\rho\left(\mathrm{kg} / \mathrm{m}^{3}\right)$ & 3500.2 & $3609^{(2)}$ \\
\hline $\mathbf{T i}_{\mathbf{4 0}} \mathbf{A l}_{\mathbf{6 0}}$ & $\mathrm{a}(\AA)$ & 2.792 & 2.828 \\
\cline { 2 - 4 } & $\mathrm{c}(\AA)$ & 4.028 & 4.064 \\
\cline { 2 - 4 } & $\mathrm{V}\left(\AA^{3}\right)$ & 314.0 & 325.0 \\
\cline { 2 - 4 } & $\rho\left(\mathrm{kg} / \mathrm{m}^{3}\right)$ & 3773.2 & $3880^{(2)}$ \\
\hline
\end{tabular}

\begin{tabular}{|c|c|c|c|c|c|c|c|c|}
\hline & \multicolumn{5}{|c|}{ Computation } & Experiment & $\%$ deviation & Others \\
\hline \multicolumn{9}{|l|}{ Ti32Al 68} \\
\hline & $\mathbf{E}$ & B & $\mathbf{G}$ & $\mathbf{M}$ & $\mathbf{N}$ & $\mathbf{E}$ & $\mathbf{E}$ & $\mathbf{E}$ \\
\hline TiAl & 174.5 & 103.1 & 72.9 & 0.214 & 1.414 & \multirow{3}{*}{$162.20^{(2)}$} & \multirow{3}{*}{0.3713} & \multirow{3}{*}{$161.99^{(7)}$} \\
\hline TiAl2 & 159.0 & 118.8 & 62.6 & 0.276 & 1.898 & & & \\
\hline Effective & 161.6 & 116.1 & 64.4 & 0.266 & 1.803 & & & \\
\hline \multicolumn{9}{|l|}{ Ti40Al60 } \\
\hline TiAl & 191.2 & 116.4 & 78.0 & 0.226 & 1.492 & \multirow{3}{*}{$166.45^{(2)}$} & \multirow{3}{*}{1.1854} & \multirow{3}{*}{$160-176^{(9)}$} \\
\hline TiAl2 & 159.0 & 118.8 & 62.6 & 0.276 & 1.898 & & & \\
\hline Effective & 164.5 & 118.4 & 65.2 & 0.267 & 1.816 & & & \\
\hline
\end{tabular}


The morphology of intergranular phase strongly influences the overall mechanical properties of a polycrystalline composite [10]. In a multiphase alloy, the value of Young's modulus is determined by the specific moduli of the phases and by their volume fractions. For a two-phase alloy, the relationship is given as [11]:

$$
E=V_{1} E_{1}+\left(1-V_{1}\right) E_{2}
$$

where $E_{1}$ and $E_{2}$ are the Young's moduli of the two phases (1 and 2) respectively, and $V_{1}$ is the volume fraction of phase 1.

Since the mole concentration of Al in our study was $47-68 \%$, the phase diagram of Fig. 3a confirms that only the two phases ( $\mathrm{TiAl}$ and $\left.\mathrm{TiAl}_{2}\right)$ will exist. With the help of Fig. 2, we plotted the graphs of number of pixels against grey scale for both $\mathrm{Ti}_{32} \mathrm{Al}_{68}$ and $\mathrm{Ti}_{40} \mathrm{Al}_{60}$, which are shown in Fig. $3 \mathrm{~b}$ and c, both of which confirm that the $\mathrm{TiAl}_{2}$ is highly dominant in both the two concentrations. The approximate areas under these curves were calculated through integration using the trapezoidal rule. $\mathrm{The}^{\mathrm{TiAl}} \mathrm{T}_{2}$ accounted for $83 \%(0.83)$, while the TiAl accounted for $17 \%(0.17)$.
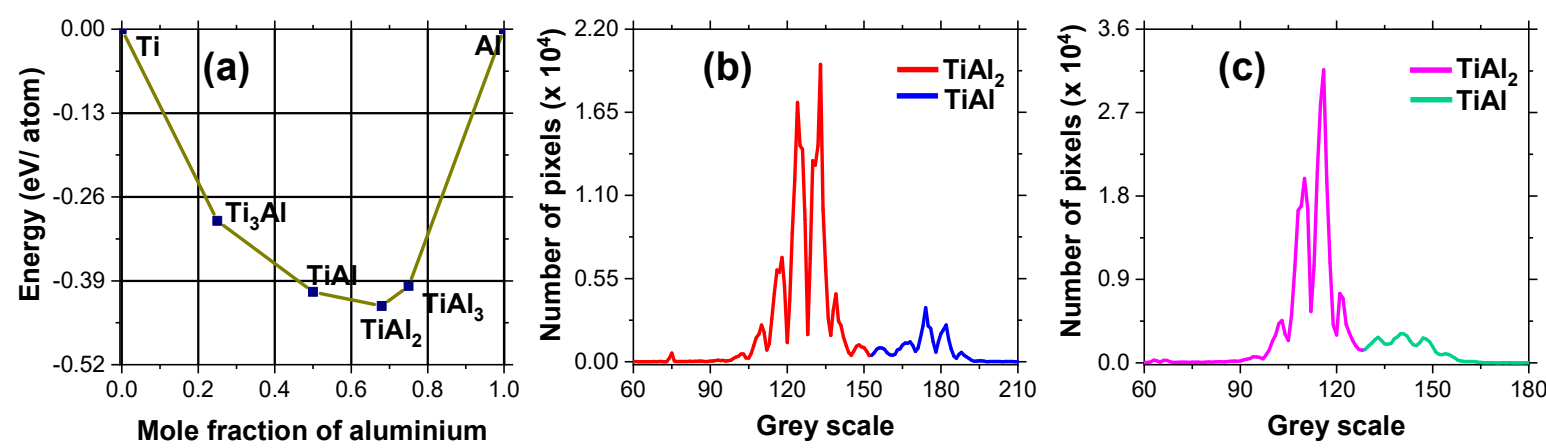

Fig. 3: (a) Computed phase diagram showing different stable phases of the Ti-Al binary alloy at different concentrations of aluminium (b) Curves enveloping the pixel histograms of SEM images. They are representative of the fraction between TiAl and 
$\mathrm{TiAl}_{2}$ for the $\mathrm{Ti}_{32} \mathrm{Al}_{68}$ alloy and (c) Volume fraction between $\mathrm{TiAl}$ and $\mathrm{TiAl}_{2}$ for the $\mathrm{Ti}_{40} \mathrm{Al}_{60}$ alloy.

With the help of Eqn. 2 and the values from Fig. $3 \mathrm{~b}$ and c, we calculated the effective values of the Young's moduli of the binary alloys at the two concentrations, which are also presented in Table 1. The values of the Youngs's moduli in the experimental study are very close to those of the computational study. The closeness between the experimental and computation values of the Young's moduli in this study is a verification of the experimental method that was employed in our previous study.

The values of the Poisson's ratio show that the TiAl phase of both the $\mathrm{Ti}_{32} \mathrm{Al}_{68}$ and $\mathrm{Ti}_{40} \mathrm{Al}_{60}$ are brittle, since their values are less than 0.27 . However, the $\mathrm{TiAl}_{2}$ phase is ductile, since its value is more than 0.27 . The effective of the two phases gave values that are less than 0.27 for both $\mathrm{Ti}_{32} \mathrm{Al}_{68}$ and $\mathrm{Ti}_{40} \mathrm{Al}_{60}$ alloys, although they are very close to the 0.27 value. On the other hand, the calculated effective values of the Pugh's ratios indicate that both the alloys are ductile, since the values of $\mathrm{n}$ are more than 1.75 .

\subsection{Conclusion}

We have successfully verified the experimental values of the elastic moduli of the two binary alloys using ab initio calculations and the general rule of mixtures. The densities of the alloys were affected by the percentage composition of Al in the alloy. The Pugh's ratio showed that both the alloys are ductile, with the $\mathrm{Ti}_{40} \mathrm{Al}_{60}$ alloy being more ductile. The calculated values of the Young's moduli were found to be in perfect agreement with those of the experimental study. The ductile nature of the Ti-Al alloys as well as their high Young's moduli give a class of materials for the aeronautics and automotive industries. 


\section{Acknowledgement}

The authors would like to thank the Centre for High Performance Computing (CHPC), South Africa for providing the computational resources for performing the ab initio calculations.

\section{Funding}

This research did not receive any specific grant from funding agencies in the public, commercial, or not-for-profit sectors.

\section{References}

[1] S-W. Kim, J.K. Hong, Y-S. Na, J-T. Yeom, S.E. Kim, Development of TiAl alloys with excellent mechanical properties and oxidation resistance, Mater. Des. 54 (2014) 814-819.

[2] D. Chanbi, L.A. Amara, E. Ogam, S.E. Amara, Z.E.A. Fellah, Microstructural and mechanical properties of binary Ti-rich Fe-Ti, Al-rich Fe-Al and Ti-Al alloys, Materials $12(2019) 1-16$.

[3] B.W. Levinger, Lattice parameters of beta titanium at room temperature locality: Synthetic sample at T $=298 \mathrm{~K}$, known as the beta phase. J. Met. 5 (1953) 195.

[4] A.S. Gornakova, B.B. Straumal, A.N. Nekrasov, A. Kilmametov, N.S. Afonikova, Grain boundary wetting by a second solid phase in Ti-Fe alloys, J. Mater. Eng. Perform. (2018) https://doi.org/10.1007/s11665-018-3300-3.

[5] J.P. Perdew, A. Ruzsinszky, G.I. Csonka, O.A. Vydrov, G.E. Scuseria, et al., Restoring the density-gradient expansion for exchange in solids and surfaces, Phys. Rev. Lett. 100 (2006) 136406. 
[6] N. Ongwen, E. Ogam, H.O. Otunga, Ab initio study of elastic properties of orthorhombic cadmium stannate as a substrate for the manufacture of MEMS devices. Mater. Today (in press). https://doi.org/10.1016/j.mtcomm.2020.101822.

[7] Y. Wen, L. Wang, H. Liu, L. Song, Ab initio study of the elastic and mechanical properties of B19 TiAl, Crystals 7 (2017) 1-11.

[8] J. Haines, J.M. Leger, G. Bocquillon, Synthesis and design of super hard materials, Annu. Rev. Mater. Res., 31 (2001), 1-23.

[9] Y-W. Kim, Intermetallic alloys based on gamma titanium aluminide, J. Met. 41 (1989) 24-30.

[10] S.V. Zherebtsov, E.A. Kudryavtsev, G.A. Salishchev, B.B. Straumal S.L. Semiatin, Microstructure evolution and mechanical behaviour of ultrafine Ti-6Al-4V during lowtemperature superplastic deformation. Acta Mater 121 (2016) 152-163.

[11] Y.L. Zhou, M. Niinomi, T. Akahori, Effects of Ta content on Young's modulus and tensile properties of binary $\mathrm{Ti}-\mathrm{Ta}$ alloys for biomedical applications. Mater. Sci. Eng. A 371 (2004) 283-290. 